Research Article

Paola Derudas*, Åsa Berggren

\title{
Expanding Field-Archaeology Education: The Integration of 3D Technology into Archaeological Training
}

https://doi.org/10.1515/opar-2020-0146

received December 7, 2020; accepted May 31, 2021

Abstract: This contribution analyses and discusses the use of 3D technology in education and learning. Basing the discussion on a case study performed during two seasons of a field school for 1st-year archaeology students, we explore how to expand traditional didactic programs by developing and testing a web-based system for educational purposes. We examine how these technologies can be used as educational means and supporting tools during an excavation; how universities can incorporate these technologies into pedagogy. We investigate whether the combination of these technologies with a successful pedagogical theory could promote students' comprehension of the reflexive approach and engagement with the interpretative process.

We introduced the students to a complete excavation methodology, including excavation, documentation, data management, and interpretation. Alongside the traditional documentation, a digital approach was added, with 3D technologies and an Interactive Visualisation System that allows fully three-dimensional reasoning from the beginning and throughout the whole archaeological process. Preliminary results show that students easily incorporate 3D documentation into their toolbox for analysing and visualising the material and understand both the possibilities and limitations of the system. However, we identified some limitations in the students' use of the system. Together with the students' feedback, we will use them to develop it further and discuss its use in education.

Keywords: 3D-technology, education, fieldwork, interpretation, reflexive process

\section{Introduction}

The matter of pedagogy in archaeology has received considerable critical attention: recently, there has been renewed interest in addressing the discussion about the way teaching approaches can affect learning (Ambrose, Bridges, DiPietro, Lovett, \& Norman, 2010; Fox, 1983; Kreber, 2002; Trigwell, 2006) and on the importance of deep approach to learning.

Recent research has investigated contemporary pedagogical theories (Al Khabour, in press; Colaninno, 2019), emphasising the significance of archaeology pedagogy to produce better archaeological knowledge

Article note: This article is a part of the Special Issue on Art, Creativity and Automation. Sharing 3D Visualization Practices in Archaeology, edited by Loes Opgenhaffen, Martina Revello Lami, Hayley Mickleburgh.

\footnotetext{
* Corresponding author: Paola Derudas, Department of Archaeology and Ancient History, Lund Univeristy, Tunnbindaregatan 3, Lund 22736, Sweden, e-mail: paola.derudas@ark.lu.se

Åsa Berggren: Department of Archaeology and Ancient History, Lund University, Sydsvensk Arkeologi AB, Lund, Sweden, e-mail: asa.berggren@ark.lu.se

ORCID: Paola Derudas 0000-0003-0069-7461; Åsa Berggren 0000-0003-2700-4143
}

Ә Open Access. ( 2021 Paola Derudas and Åsa Berggren, published by De Gruyter. (c) BY Commons Attribution 4.0 International License. 
(Cobb \& Croucher, 2014). And current studies reflect on the importance of technology in archaeological education (Agbe-Davies, Galle, Hauser, \& Neiman, 2014; Dell'Unto, 2018; Evans \& Daly, 2006; Lock, 2006; Papadopoulos, Chrysanthi, \& Murrieta-Flores, 2012; Opitz \& Limp, 2015). However, although some research has been conducted (Garstki, Larkee, \& LaDisa, 2019; Peuramaki-Brown, Morton, Seitsonen, Sims, \& Blaine, 2020), the integration of 3D visualisation systems with successful pedagogical theories that promote deeplearning approaches in field-archaeology courses is missing. Deep-learning approaches, which are associated with higher quality learning outcomes, occur when the teacher encourages self-directed learning and makes time for students to interact and discuss problems, provokes debate, and questions students' ideas developing a conversation with them (Trigwell, 2006, pp. 108-113).

This article explores the ways Project-based learning (PBL) activity of archaeological excavation is combined with the use of technology as a means to boost students' deep and active approaches to learning, increase their confidence with the latest digital methods applied to archaeology, and provide preliminary insight into the development of such tools and undergraduate student use.

\section{Archaeology and Pedagogy}

A significant body of literature recognises the importance of a pedagogical deep-learning approach in education and demonstrates how the teaching strategies can influence learning (Ambrose et al., 2010; Fox, 1983; Kreber, 2002; Trigwell, 2006). The teachers, who cannot directly observe learning while it is happening (Fox, 1983, p. 151), need to combine theories and the design of effective course activities to achieve the motivation associated with deep-learning. Combining the two, indeed, allows the students to have an intrinsic interest in the tasks and expectations of enjoyment in carrying them out (Trigwell, 2006, p. 109).

The importance of research on pedagogy in archaeology is proved by the growth of studies and inquiries (Hamilakis, 2004; Lea, 2020; Synnestvedt, 2015). Some studies focus on the application of already existing pedagogical theories to archaeology (al Kahabour, 2020; Colaninno, 2019), and others aim at the definition of new theories (Cobb \& Croucher, 2014). And the increased diffusion of technologies throughout the archaeological practices also affects the research on archaeology pedagogy and influences some pedagogical theories.

Scholars acknowledge the importance of technologies in archaeological education, considering that computer-assisted learning helps to create a fruitful pedagogical environment (Evans \& Daly, 2006), arguing that digital curation should be a pervasive epistemic-pragmatic activity encompassing the entire archaeological process (Dallas, 2015, p. 176), and recognising the strength of 3D models over more distanced and static 2D contents (Opitz \& Limp, 2015, p. 357). Scholars, moreover, emphasise the importance of technologies in the production of archaeological knowledge (Dell'Unto, 2018, p. 58) and admit these are an undervalued resource for education (Agbe-Davies et al., 2014, pp. 837-855). Recent experiences in the use of technologies in archaeological education attest to significant growth of students' knowledge and skills (Agbe-Davies et al., 2014, p. 855; Derudas, Dell'Unto, Callieri, \& Apel, 2021), demonstrating that they should be included in the archaeology curriculum.

However, to let the students reach a deep approach to learning, achieve critical reasoning, and promote the comprehension of a reflexive approach and an engagement with the interpretative process, it is important to combine technologies with a successful pedagogical theory. A recent review of the available online learning platforms and tutorials in digital archaeology reveals some of their limits, such as a focus on technical aspects more than on a critical evaluation of wider intellectual ramifications and impact (Daems, 2020, p. 90).

Yet, there are promising applications that combine digital resources and the attention to the epistemological possibilities of digital archaeology, which include pedagogical practices and digitally informed habits of thought (Daems, 2020, pp. 91-92). For example, the pilot project by Garstki et al. is to assess the efficacy of digital 3D artefact and excavation models for teaching via the introduction of three-dimensional archaeological contents implemented in an immersive system (MARVL). The professor uses the system to guide a virtual experience for integrating and supplementing the lectures' existing structure. According to 
the authors, the use of such a new media in the course can attract a wider number of students without affecting the main purpose of the course, which is to develop broad critical thinking skills crucial to interpreting the past by analysing the material culture (Garstki et al., 2019, pp. 48-52).

Technology-enabled learning is another example of the integration of technologies within archaeological pedagogy: it combines various teaching activities and exploits digital technology to create "enthusiastic, engaging, respectful and accessible educational experiences” (Peuramaki-Brown et al., 2020, p. 1).

Such examples reveal a gradual increase in interest in the use of technologies in archaeological education. However, more attention to the pedagogical aspects of such implementations would help to define pragmatic educational strategies in field-archaeology courses. In our educational experience, we aimed at combining the PBL activity of archaeological excavation with the use of technology as a means to boost students' deep and active learning and to increase their confidence with the latest digital methods applied to archaeology.

Among pedagogical theories, PBL is considered relevant for promoting a deep-learning approach, achieved through engaging with authentic tasks and learning by doing (Bell, 2010; Helle, Tynjälä, \& Olkinuora, 2006). PBL activities, in fact, involve students' initiative in the solution of an authentic task or a problem and imply various educational activities where the teachers have an advisory role; the end product of PBL activities is commonly a report (Helle et al., 2006, p. 288). Archaeological excavations, which are authentic tasks in the form of projects by their very nature, ensure active learning and engagement.

\section{Research Problem and Aim}

Our study expects to bring an inspirational contribution to specific current research in archaeology education, combining a pedagogical approach with digital technologies. We believe it is needed for a deeper critical reflection on integrating digital technologies in archaeological pedagogy to promote a deep approach to learning, student engagement, critical thinking, and reflexivity. Considering that in academia, the use of digital technologies is widely accepted throughout the excavation process, we believe it is crucial to integrate these technologies in archaeological training based on solid pedagogical theories.

Through the experimentation of the new approach we engage with, the goal was to estimate the effects of using these technologies in the educational path of undergraduate students. We also intended to apply to archaeological education the exhortation "to think incisively about how we can use [digital systems] in ways that transform what we are accomplishing in our archaeological research" (Jackson, Motz, \& Brown, 2016, p. 179).

Nowadays, to make archaeology richer, it is not possible to separate archaeology and archaeological computing (Chrysanthi, Murrieta Flores, \& Papadopoulos, 2012, p. 7); for this reason, we intended to integrate available computer applications within the field course, a PBL experience per se. We aimed to design and give the students "a critically engaged and theoretically driven application of technological methods" (Perry \& Taylor, 2018, pp. 13-14), and we defined a documentation and data management pipeline to let the students have a complete view of the multiple practices employed in the research investigations conducted at a typical excavation.

Besides learning and practising the basics of handmade drawings and context-sheets filling-in, the students also practised artefacts and samples recording within a 3D GIS system. Finally, they used a webbased Interactive Visualisation System (IVS) created especially for them as a supporting tool while writing the report (https://www.darklab.lu.se/digital-collections/dynamic-excavation/sodra-sallerup/).

This online platform embeds the excavation components exploiting digital technologies as a reflexive tool: instantly and conveniently available information, indeed, enable archaeologists to make betterinformed decisions and interpretations (Berggren et al., 2015) and facilitating a self-reflexive attitude.

3DHOP is the tool chosen for developing the IVS of the Södra Sallerup excavation, a versatile web 3D viewer developed for the publication of Cultural Heritage three-dimensional contents that can be tailored according to one's specific needs (Potenziani et al., 2015; Potenziani, Callieri, \& Scopigno, 2018).

The Södra Sallerup IVS consists of an online interface that enables access to the 3D dataset of the entire excavation area and of the numerous excavation units excavated by the students. Students can visualise 
each three-dimensional model independently, thanks to the possibility offered by 3DHOP: we managed and customised the appearance and the visibility of the models to be displayed, allowing the students to choose whether to visualise more 3D models on the screen simultaneously. We implemented a set of tools to let the students perform basic analysis such as visualisation of solid colours, control of light parameters, measurement of distances, retrievement of coordinate information, and sectioning of planes. Thanks to these tools and the possibility to save screenshots, the students could obtain analytical information and build visual descriptions for the narrative of their interpretation. We considered that the user-friendly interface of the platform designed was suitable for students with different technological backgrounds and experiences.

\section{Södra Sallerup Methodology}

The IVS has been used experimentally during two field courses organised by the Department of Archaeology and Ancient History of Lund University in 2019 and 2020. The students were on their second term of studying archaeology, and for many, this was their first experience of an archaeological excavation. This course's main components consist of one week of excavation activities and one week of post-excavation work, including processing finds and documentation and writing reports. The excavation took place in Södra Sallerup, just East of the city of Malmö in Southern Sweden. The area is known for Neolithic flint mines (Nielsen \& Rudebeck, 1991; Rudebeck, 1994), and the excavated object is a stratified deposit dated to the Bronze and Iron Ages (Berggren, forthcoming). The deposit consists of a main, upper layer covering an area of $15 \times 11 \mathrm{~m}$ and some smaller lower layers, in all about $0.2-0.3 \mathrm{~m}$ deep. The deposit is a suitable object for inexperienced students, with uncomplicated stratigraphy and a fair amount of finds consisting of pottery sherds, fragments of animal bones, and reused or redeposited Neolithic flint implements. The layers were excavated in a grid of $1 \mathrm{~m}$ squares using a single context method, but divided into $0.1 \mathrm{~m}$ spits where they were thicker than this.

We produced two versions of the IVS, one for each campaign; they were made available for the students for the report writing during the laboratory week. In the 2020 campaign, students had access to both versions.

For the implementation of the IVS 2019, we produced twenty-eight 3D models divided as follows: two of the entire trench, before and after the excavation; twenty-four of the excavation units investigated, and two of the finds in situ (Figure 1). After conversion into the nexus compressed format (Ponchio \& Dellepiane,

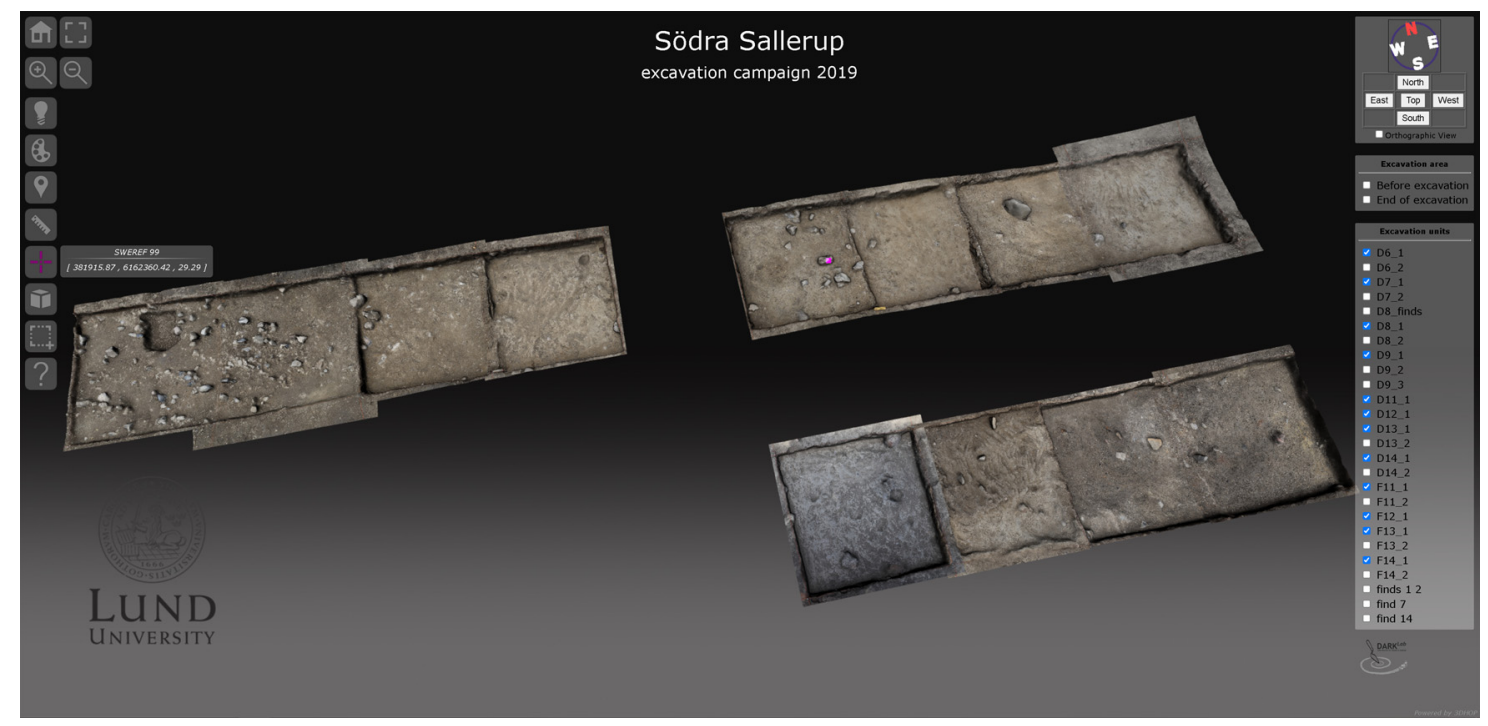

Figure 1: The 2019 interactive visualisation system of Södra Sallerup. 
2015), we uploaded the 3D models to the system. The students accessed and started to use the IVS at the beginning of the laboratory week.

During the 2020 season, we produced three models of the trench (before and after the investigation, as in 2019), twenty-seven models of excavation units, and three models of artefacts (documented in situ before their removal) and compressed them into the nexus format and added them in the system.

Unlike 2019, in 2020, we uploaded in the IVS also the models of the extents of the lower contexts/layers recorded during the excavation. These are non-compressed low-resolution models drawn directly on the 3D models of the trench and excavation units and visualised in the system with a transparent colour that enables to recognise the contexts' extension (Figure 2) instantly.



Figure 2: The 2020 interactive visualisation system of Södra Sallerup.

In this version of the system, the students were able to access the final state of 2019 excavation, too, both on a trench and excavation-unit level.

We presented the IVS to the students as an additional tool for writing the report, together with the hand-written documentation they themselves produced and the 3D GIS.

We had time to evaluate and learn from the first implementation while planning the second during the 1 year gap between the two campaigns. This possibility led us to design a more in-depth evaluation of the student learning process during the second campaign concerning the various documentation methods. We carried out this evaluation through a questionnaire given to the students at the end of the course in 2020.

\section{Application}

\subsection{Excavation 2019}

Twenty-two students excavated 12 one-per-one-meter excavation units in pairs (Figure 3). The recordings of the trench and the deposit were performed with GPS, total station, and photogrammetric acquisition for the generation of a three-dimensional model (through image-based modelling techniques). In the daily fieldwork, the students produced handmade drawings of sections and measured finds and sample locations via total station. 


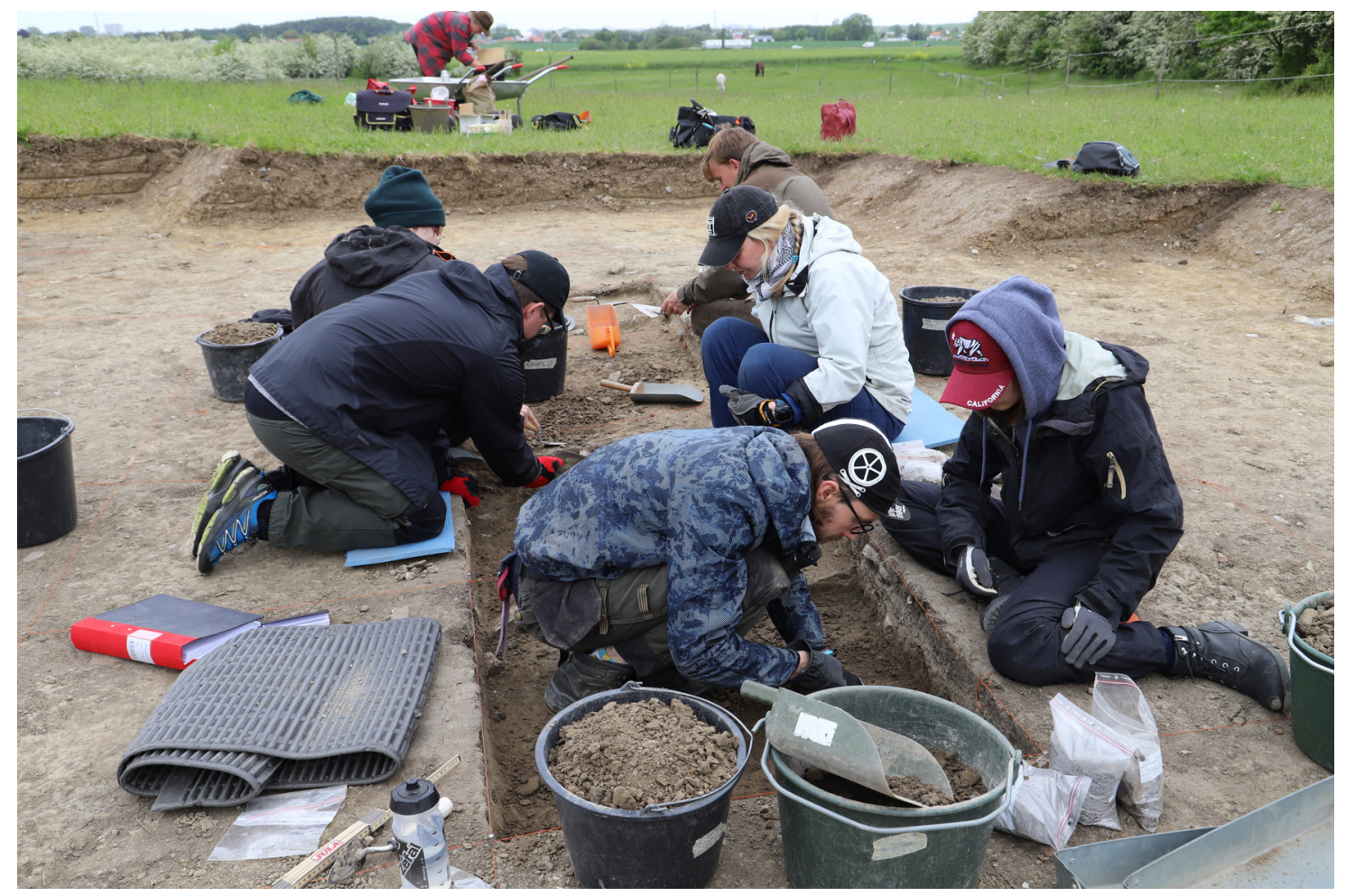

Figure 3: Photo from 2019 excavation, overview of students excavating. Photo: Paola Derudas.

After a brief training on the photogrammetric acquisition process and a demonstration of the data processing, the students were invited to take photographs of their excavation units and of relevant finds for the generation of three-dimensional models. The students followed the data processing (from the 3D model generation to its implementation in the 3D GIS system) together with one of the teachers, who also performed the survey-data download, processing, and 3D GIS system implementation because of time constraints. On the first day of the post-excavation week in the laboratory, we shared the IVS of the excavation with the students, providing them with information on its functionalities (https://models.darklab.lu.se/ dig_excav/Sallerup19/SodraSallerup19.html).

The students worked in groups and wrote five reports. After the short introduction to the IVS, they were able to use the system without problems: they could easily access and navigate the complete stratigraphy recorded, exploring the high-resolution 3D models, and used it both for basic analysis and creating illustrations.

\subsubsection{Analysis}

During the post-excavation process, the students worked on report writing and on artefact analysis and recording, and they could do it by exploiting the visualisation system. They could virtually go back to their excavation unit, observe its characteristics and stratigraphic relationships, and retrieve quantitative and spatial information useful for their report writing.

The students were instructed how to use the IVS system during the first day of the post-excavation week, and after this, no one asked for more instructions. The students understood it quickly and had no major problems in using it, even though they had had no previous similar experience or technological skill. A systematic review of their use of the IVS was not performed, so we have no data on the extent of this use. However, we could observe the students during this work and could see that they used the system. In one of 
the reports (Bergman, Dahlström, Larsson, \& Lindahl, 2019), the possibilities of the visualisation system are mentioned, such as turning layers off and on, taking measurements, and locating the exact position of finds. We can see that this particular report and an additional one (Andersen, Andersson, Ferreira, \& Petersen, 2019) state the coordinates for various finds, and we conclude they used the system to retrieve this data. Moreover, in two reports (Andersen et al., 2019; Bergman et al., 2019), it is mentioned how the students used the 3D visualisation to analyse the spread of a stone layer that extended over several squares, excavated by the two different groups (Figure 4). The squares were not excavated at the same pace, so the stone level was not simultaneously visible in neighbouring squares during excavation. Instead, the stones were made visible together in the 3D model and the illustration. The students thus used the system to merge parts of an entity that was fragmented by the excavation to better understand it and created an image of this entity using the system.



Figur 24: 3D modellering över stenformationen, D6 från vänster till ruta D8 $i$ höger.

Figure 4: The picture, taken from one of the reports (Bergman et al., 2019), shows the students' use of IVS/3DHOP to visualise the extension of the stone layer in three units. They have combined 3D models of their own unit and the neighbouring group's units.

Another group of students (Ahnlund Malmberg et al., 2019) also reflected on their experience of subjectivity during the process of interpretation. They realise that two individuals may experience soil characteristics differently, and they acknowledge their difficulty in comparing their interpretations of different units. However, they did not try to overcome this difficulty by combining the units in the IVS and thus comparing them in the image. Other students did combine models created at different times (e.g. Svensson, Sarpehöök, Wendt, \& Radtke, 2019), but it is not clear whether the depicted levels had been simultaneously visible and the combined 3D image was used for interpretation.

\subsubsection{Illustrations}

In all five reports of 2019, the IVS was used to create illustrations of the deposit and the excavated squares by screenshots. In most of the reports, two or three such illustrations were used, and in one report (Bergman et al., 2019), eight illustrations were used. The illustrations varied in view and contents (Table 1).

It is interesting that the angled view (most with a slightly slanted angle and some with a skewed angle - see examples in Figure 5) is used in as many as 50\% of the overview cases, considering the orthographic view and the vertical plane view are standard in archaeological documentation and illustration. As this is their first excavation, the students may not be familiar with this norm and thus act more freely when choosing a view. They may have chosen the angled view as they found it is illustrative and nice, but also because it felt most natural, as the angle is similar to the view of a person standing or sitting beside 
Table 1: The different uses of IVS illustrations in the student reports of 2019

\begin{tabular}{lll}
\hline Content & View & Number of illustrations \\
\hline Overview whole deposit & Orthographic & 1 \\
Overview whole deposit & Angle & 1 \\
Overview of 1-3 squares & Orthographic & 7 \\
Overview of 1-3 squares & Angle & 7 \\
Detail of find or stone concentration & Orthographic & 2 \\
\hline
\end{tabular}


Figure 5: Examples of views used by the students (Ahnlund Malmberg et al., 2019; Petersén et al., 2019) (a) and (b) slightly skewed angled views; (c) orthographic view.

the square. It may also have been chosen because it gives a view of the profiles around the square and thus illustrates the thickness of the excavated layer.

In one of the two overviews of the whole deposit (Petersén, Ekman, Vitale, \& Osvath, 2019), the location of the excavated squares in the deposit was highlighted with a red rectangle (Figure 5c). This was the only case when the students used some kind of amendment to the image taken from the IVS. The students of 2019 did not use the images to show explicit interpretations or point to certain issues discussed in the text, with the exception of the distribution of the stone layer mentioned above. We do not know whether this is because they lacked time to fully explore the possibilities of the visualisation system or because they did not understand them or did not think of them. However, in one of the reports (Ahnlund Malmberg et al., 2019), the students explicitly state that they think the addition of the 3D images made their reports more scientific.

To conclude, some interesting observations we made after the 2019 excavation concern the choice of view of the students being somewhat unconventional and the use of the system to visualise something they could not see during excavation but was instead visible in the model. This possibility "to fully integrate excavation and postprocessing in a complex spatial analysis reconnecting contexts excavated on different occasions in the field process" (Wilhelmson \& Dell'Unto, 2015) has been mentioned as one of the benefits of virtual visualisation. 


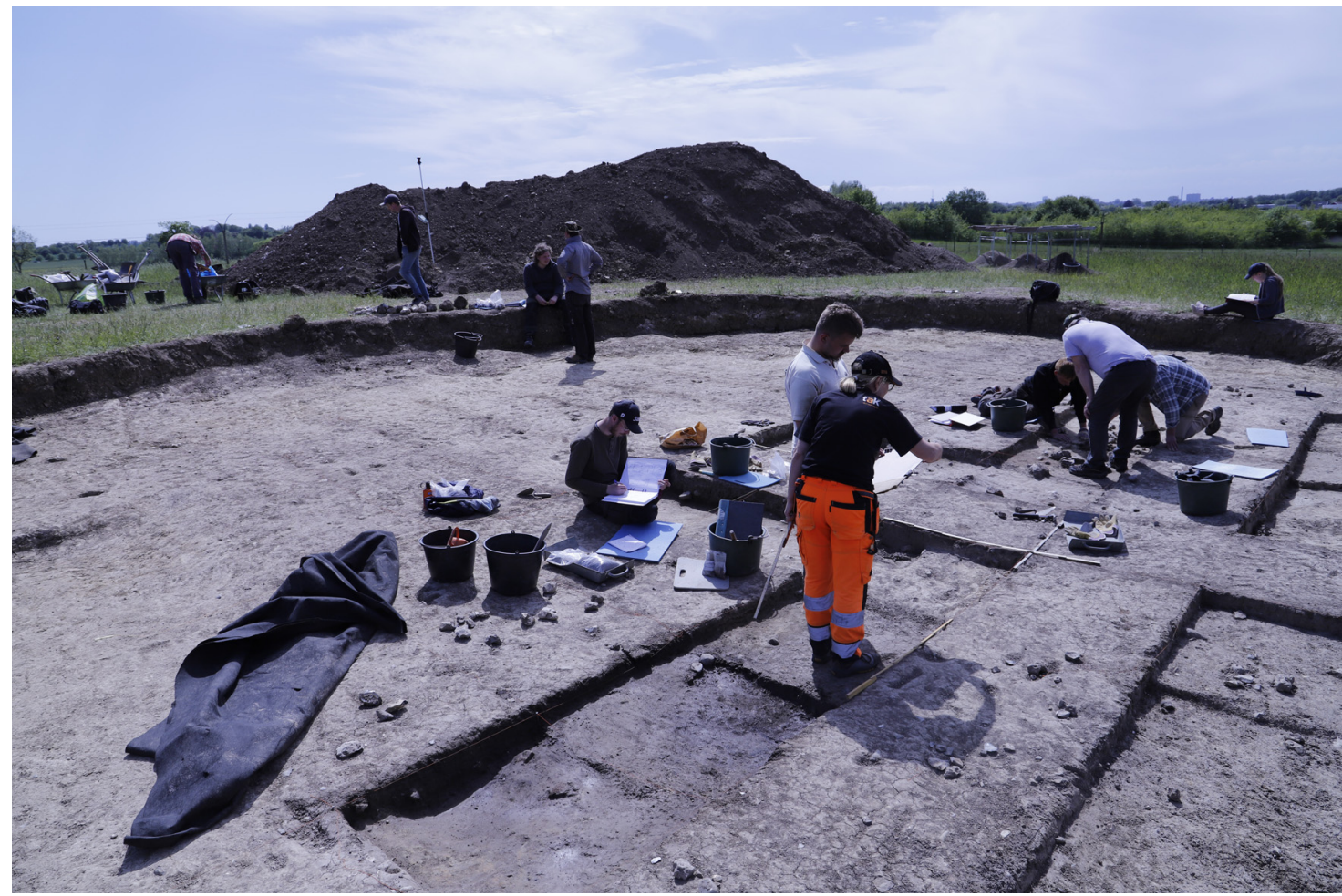

Figure 6: Photo of ongoing excavation in 2020. Photo: Paola Derudas.

\subsection{Excavation 2020}

Ten students excavated one-per-one-meter excavation units each (Figure 6). The 2019 campaign IVS was used at the trench's edge to describe and show the students the stratigraphy and progress of the previous year's investigation during the first day of fieldwork, and it was made available to them from the beginning of the field activities, together with the excavation reports of their colleagues of 2019.

We employed the same documentation and data management methodologies and procedures used in 2019. On the first day of the post-excavation, we shared the 2020 IVS with the students, showing them its functionalities and possibilities. Compared to the 2019 excavation campaign, the 2020 IVS had some small improvements: together with the models of the excavation units, the students could visualise models of the contexts (layers) with transparent colours (Figure 7) and could directly save screenshots via a dedicated button (https://models.darklab.lu.se/dig_excav/Sallerup20/SodraSallerup20_contexts.html).

The students were divided into groups and wrote three reports. As during the previous year, the students used the IVS to analyse the material as well as make illustrations. In addition, they could access the previous year's (graphic) documentation. Furthermore, we provided the students with the scheme of a standard report they could use as "scaffolded instructions" for writing their report, and they had access to the previous year's Södra Sallerup reports as well.

At the end of the two-week field course, we delivered an online questionnaire (https://docs.google. com/forms/d/1kqY8_4rE0OszM3py4ci9oBwOHACUE1RoQPIwnKYmp8Q/edit?usp=drive_web) for the students to answer anonymously, in order to assess quantitatively and qualitatively the validity of the pedagogical approach employed within the course. We asked them about the various documentation methods used, if they found the acquisition easy or difficult, and how they used the results. Moreover, we compared what the students said in the questionnaires about the documentation and how it was used to the actual reports and what they show us about the actual use of the documentation. The results of the questionnaire are presented below. 

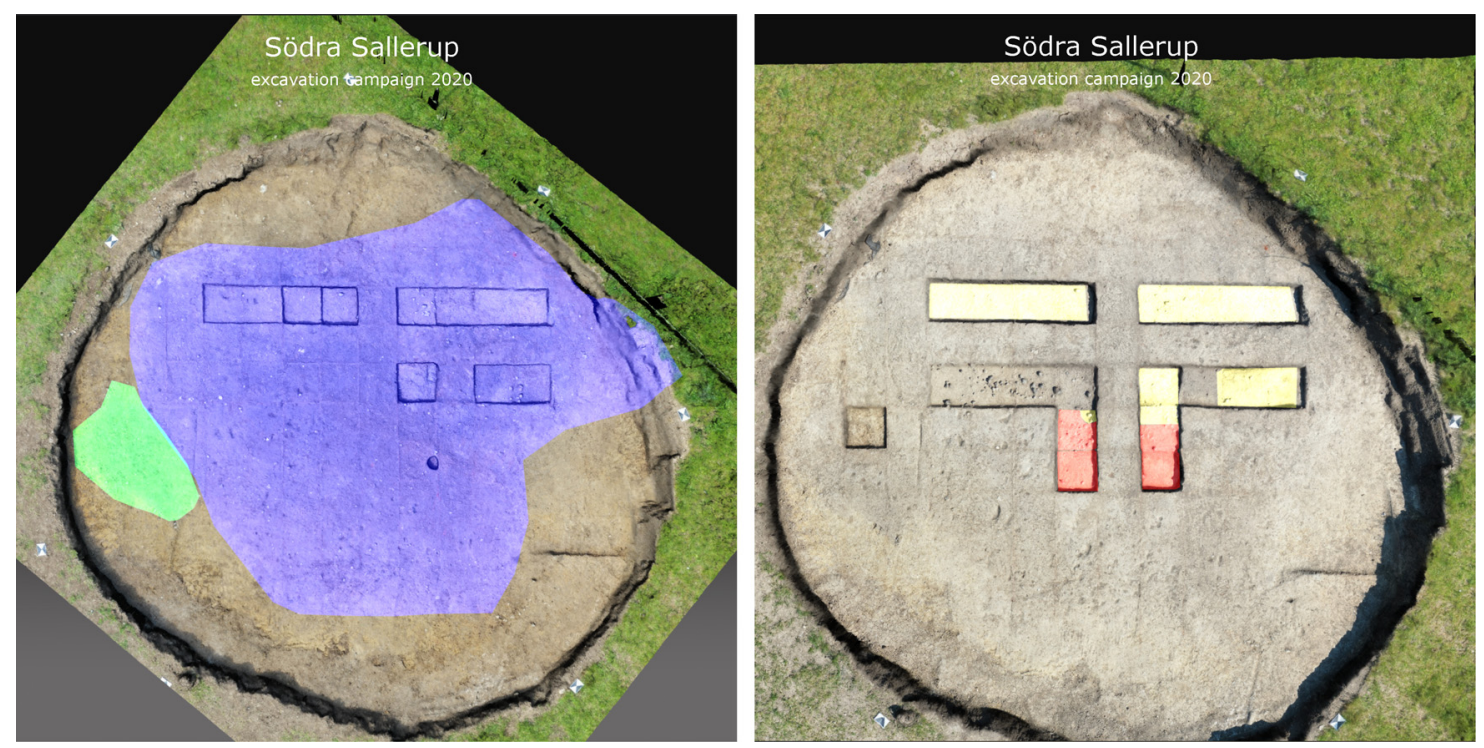

Figure 7: The IVS displays, on the left, contexts 101 and 103 at the beginning of the excavation; on the right, contexts 102 and 104 at the end of the excavation investigation. Illustration: Paola Derudas.

\subsubsection{Acquisition}

As the students used various documentation methods, from hand drawing to photogrammetry, we wanted to enquire about their experience of the acquisition of these records. In the questionnaire, we asked the students to define the acquisition of both hand-drawing and image-based modelling. The students found both methodologies of archaeological documentation easy. Still, there is a slight difference, where the students show greater ease at hand drawing. This is interesting, as drawing on graphic millimetre paper to a scale takes some skill in understanding the scale and how it translates to the paper. On the other hand, image-based modelling is a highly automated process once the photographs are taken. It is rather a matter of understanding which software to use and how to start the process. However, to really grasp the impact of the digital method on the quality and character of the data, a full understanding of the digital practice is necessary. This kind of understanding is crucial regardless of which illustration method is used, digital or manual (Morgan \& Wright, 2018). The reason why the students felt more at ease with the hand drawing is perhaps that it seems more familiar using pen and paper, even though the scaling was not familiar to them. Another reason may be the familiarity with hand drawing they achieved during the week, drawing their sections together with the other students, while the 3D data was processed by one of the teachers while the students observed. The students were only directly involved in taking the photographs. A more comprehensive and practical hands-on introduction to the digital acquisition and process would have been needed for a fuller understanding of this part of the documentation on the part of the students. However, within the limits of the one-week fieldwork, this was not feasible.

\subsubsection{Analysis}

In the questionnaire, the students were asked to rate how easy or difficult they found using the IVS as well as state how they used it. All the students stated they found it easy to use, even if in different hues. They responded that they used it mostly to analyse the stratigraphy and to take measurements (70\%) and to understand the connection to other excavation units, and to understand the change in the elevation of the excavation unit (60\%); half of the students also used it to understand the location of their excavation unit in relation to the greater context and $40 \%$ to understand the orientation of the excavation unit and to analyse 
10. How did you use the 3DHOP system to analyze and understand your excavation unit?

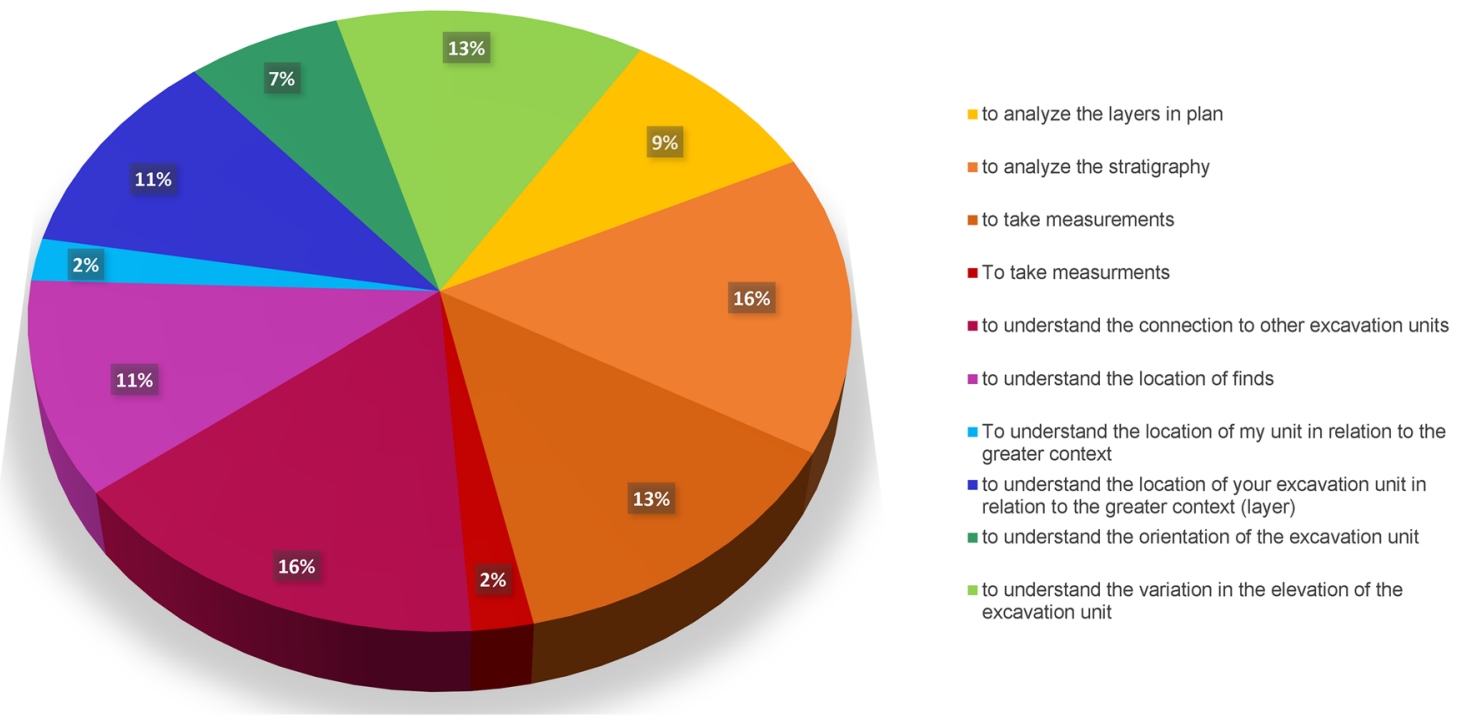

Figure 8: Question 10 illustrates its use in analysis and understanding of the excavation unit.

the layers in plan (Figure 8, question 10). However, in none of the reports of 2020, the coordinates of finds recorded in situ are mentioned. It seems they did not use the positioning tool of the IVS.

The students also stated that they used the IVS for visualising the 3D models of the previous excavation. They did this mostly to compare the characteristics of their excavation unit with those of a close one previously excavated (ca 86\%); some used it to compare the thickness of the layer excavated in their excavation unit with that of a close one previously excavated (50\%) (Figure 9, question 12).

Half of the students stated they used the IVS just some times to visualise the previous excavation models, and only a few used it many times for this purpose. This is interesting as there are no references to the previously excavated units in the reports, nor are there any illustrations comparing the units from the two campaigns (see more below).

12. Have you used the 3DHOP models from the previous year's excavation? If so, what especially have you used it for?

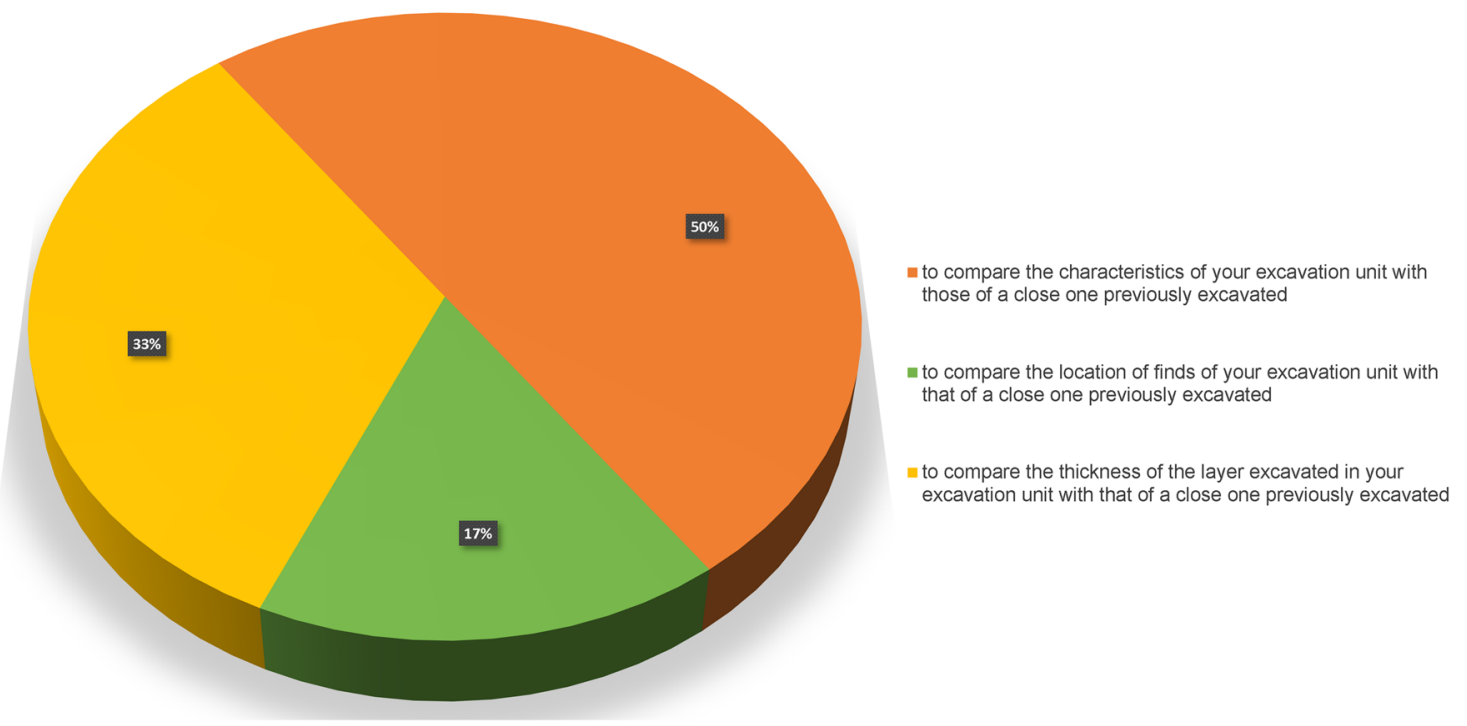

Figure 9: Question 12 illustrates its use for the visualisation of the models of the previous year's excavation. 
11. How did you use the 3DHOP system to visualize your excavation unit in the report?

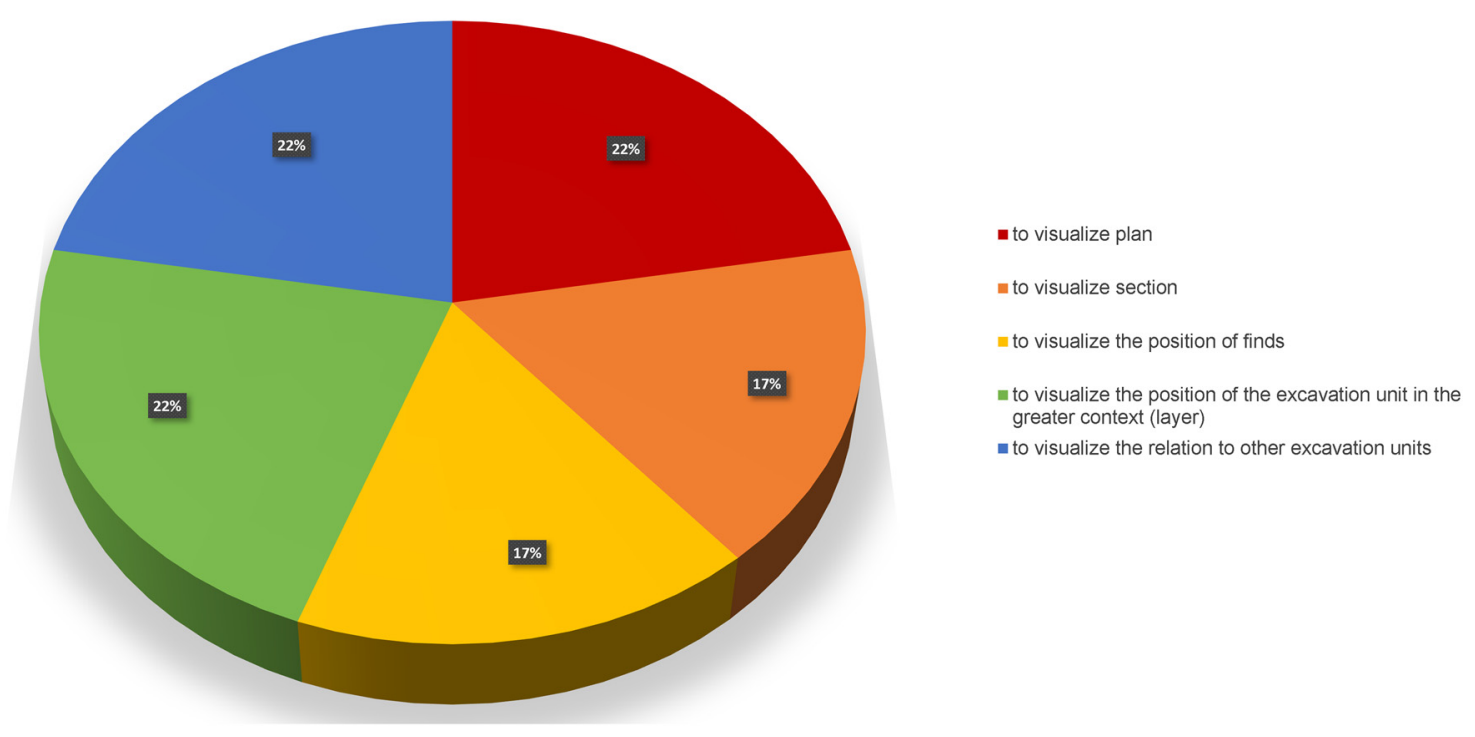

Figure 10: Question 11 represents the tools of students' preferences.

Among the tools embedded in the IVS, the students identified the measuring tape as the most useful one, followed by the plane sectioning and the light control (Figure 10, question 15). This is also worth noting, especially as the plane sectioning is not used to any great extent in the illustrations (see more below).

Many of these uses that are stated in the questionnaire are not directly visible in the reports. We cannot determine how the students performed their analysis and came to their conclusions. So we asked how they used the IVS system when they wrote the reports. According to their answers, they used the IVS to retrieve data such as measurements, coordinates, and relations. To a lesser degree, the IVS was used to visually check details of the excavated unit and an even lesser degree to visually check details of finds. Moreover, we observed the students during the post-excavation work and know they used it. As the students during the previous year, they needed no help once they had been instructed. Logically, no one stated in the questionnaire that they found the system difficult to use.

\subsubsection{Illustrations}

The students were asked how they used the IVS to create illustrations for their reports. Visualising in plan, relation to other units and position within the greater context were stated as the most common uses, but visualising sections and position of finds were also quite common. This is interesting as the illustrations in the reports do not fully correspond with this result of the questionnaire. Generally, the students seem to overestimate their use of the IVS when creating their illustrations. For example, as seen in Table 2, the section view is only used in one illustration (Dahlberg, Svensson, \& Parker, 2020, Figure 6), but three

Table 2: The different uses of the IVS for illustrations in the 2020 student reports

\begin{tabular}{llc}
\hline Content & View & Number of illustrations \\
\hline Overview of deposit & Orthographic & 2 \\
Overview of 1-3 squares & Orthographic & 13 \\
Section of 1 square & Vertical plane view & 1 \\
Detail of find & Orthographic & 2 \\
\hline
\end{tabular}


students stated they used it. Moreover, only one illustration in the reports shows a detail of a find in situ taken from the model (Ahlberg, Gisbertz, Lindström, \& Olsen, 2020, Figure 13), and three students stated they used this kind of illustration. Four students stated they used the IVS to illustrate the position of their unit in the greater context, but only two illustrations show this position (front page Dahlberg et al., 2020; Ahlberg et al., 2020, Figure 1). One explanation for this discrepancy may be that the students answered, thinking of their report as a group effort, even though they were each responsible for certain sections of the text. Even if only one unit was illustrated in section, all students in that group might have answered that they used this perspective. Another explanation could be that the students felt an expectation to have used the IVS to a greater extent than they actually did, as we as teachers placed much emphasis on this system.

In 2020, the students made five, six, and seven illustrations using the IVS for the three reports. The illustrations were depicting the orthographic view to a great extent. Only one illustration (Dahlberg et al., 2020, Figure 6) was of the vertical plane (Table 2).

It is interesting as $50 \%$ of the students stated they found the plane sectioning tool useful. It was just not well used for making illustrations for the reports. As the students all drew sections by hand, most of them used photos of the drawings in their reports. In total, nine illustrations depicted section drawings - in one report (Larsson Ljungström, Suominen, \& Wirestrand, 2020), the hand drawings were digitised. The single illustration showing a section from the IVS indicates that the section function may have been experienced as redundant, even though the hand drawings and the IVS section do not depict exactly the same segment of the excavated unit.

In three illustrations, the students made use of annotations, highlighting something in the image, e.g. the location of a square in the greater deposit or a find in the excavation unit (Ahlberg et al., 2020; Dahlberg et al., 2020). In one case, three models of squares were combined together in one image (Ahlberg et al., 2020) to show the layer the excavation reached, similar to the example from the previous year. However, in this case, it is not clear whether the layer was exposed in level at any point during the excavation or if the models had to be used to show the layer in the different squares together. In any case, it shows the students' capability of looking beyond their own unit, showing patterns over larger areas in the deposit.

The students of 2020 had more information and functions to work with in the IVS. First, they had the information from the previous year, but they did not make use of this in the images in their reports, e.g. showing details of nearby squares or sections. This is interesting, as $50 \%$ of them stated in the questionnaire that they looked at the previous models of nearby units during their work. Only $20 \%$ used the information in the 3D GIS system to learn more about the previous year's units.

Second, they had access to the extent of the layers of the deposit (the main upper layer and the smaller, lower layers) as graphic features in the IVS. No one used the possibility to illustrate the location of their square within the layers using these features. A new function making it possible to make the layers transparent was added during the post-excavation week. This was also not used by the students, or at least not exploited for the illustrations shown in the reports. However, the students were well-aware of the potential of the 3D documentation. One student suggests in the report that future research should recreate the topographical relationship between the deposit and other phenomena in the landscape in a 3D model (Ahlberg et al., 2020). The students also had access to the 3D GIS system, where they registered all the data. The possibilities to use this to create plans and illustrations were not used by the students, probably as they were encouraged to use the IVS.

To conclude, the students of 2020 used the IVS to produce illustrations according to archaeological norms and overestimated their use of the IVS both for analysis and the production of illustrations.

\subsection{Comparison 2019 and 2020}

It is difficult to draw conclusions with such a small sample as in this case, but we will discuss some tendencies that we can see in the data. We base the analysis and discussion on our observations of the students, the student reports of both years, and the questionnaire of the 2020 campaign. 
The students used the various records both for analysis and illustrations, including the digital data. The 3D GIS system was used to retrieve textual information on artefacts and excavation units but not visual data (the map function in ArcGIS Pro). Instead, it seems the IVS was the preferred source of visual information in both 2019 and 2020. The more realistic photographic imagery may be a reason for this preference; however, the students were probably also influenced by the importance we as teachers placed on the acquisition of the visual data by photography. In archaeological reports, GIS is often used to produce plans and other illustrations, but in this case, we see that the IVS has taken over this function entirely, even though both softwares were available to the students. It seems the IVS offered all that the students required to make their illustrations for their reports.

There are some interesting differences between the two campaigns. The IVS was used to create illustrations to a greater extent in 2020, as more illustrations were created per report. It is not clear why, as the students on both occasions seemed at ease with the system. But the students of 2020 became more familiar with it (perhaps as they saw the imagery of the system in the reports of the previous year). The 2020 students adhered to the standard archaeological views without experimenting with the visual possibilities of the system. Perhaps the students of 2020 were more adaptive to the archaeological visual conventions; however, these were not stressed by the teachers, not to hamper the creativity with the system. The students in 2020 were introduced to the IVS earlier in the course, but they did not make more varied use of it than the students during the previous year. The unconventional views were only seen in 2019. It is possible the 2019 students' attitude towards the views of archaeological images and illustrations may point to a change of archaeological illustration practices in the future, as the possibilities of easily experimenting with various angles have become available. It is worth noting that we chose a slightly angled view as the opening view of the IVS project (see Figure 11), as it was thought to provide a suitable starting point, giving the user a conception of both the horizontal and vertical planes upon opening the system. It was not a conscious idea to oppose conventional views of archaeological illustration, but rather an idea of what was most suitable.

The section function in the IVS was available to the students of the 2019 excavation, but was not used for making any illustrations (and only the one in 2020). Perhaps the IVS section images were not considered clear enough? It is also possible the hand drawings were seen as the prime source of the section illustrations, making the section function in the IVS redundant. This way, the students regard the manual and the digital as interchangeable; the conveyed information is prioritised over the choice of method.

Also, concerning annotations to illustrations, there was a small increase in 2020 from the year before and points to a greater familiarity with the system and a greater willingness to use the images to

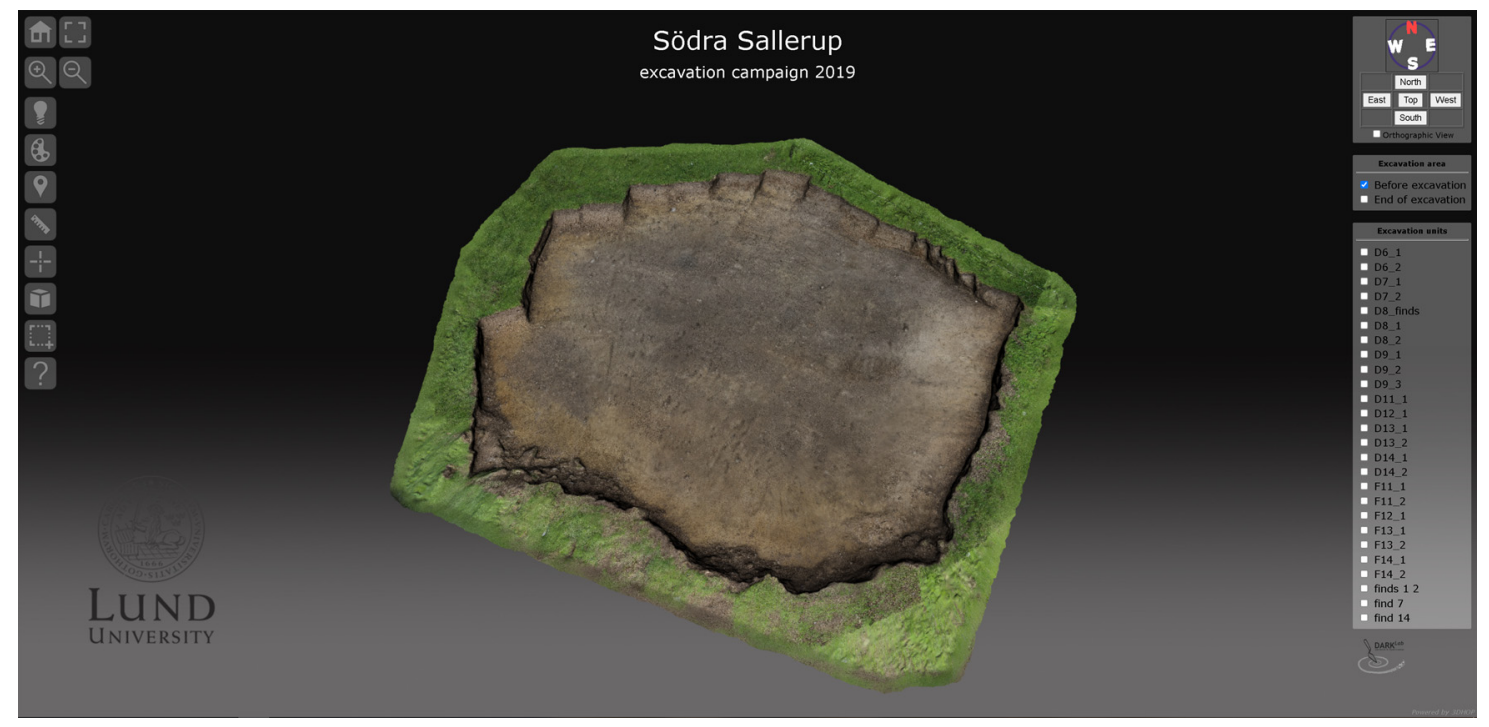

Figure 11: The interactive visualisation system of Södra Sallerup, in the centre: the canvas displaying the model; on the left: the visual and analytical tools; on the right: the available 3D models. Illustration: Paola Derudas. 
communicate a specific matter. This way, the IVS becomes a part of the students' processing of the data. However, this was not used to the fullest potential. All the reports lack discussions where the units are compared between the excavation seasons. An explanation could be connected to the fact that only two of the 2020 units were physically connected to the 2019 units. It is also a common beginner's mistake to focus on the unit at hand and not regard it in the context of the surroundings. The digital 3D visualisation system should have inspired the students to be more aware of the surrounding context, but it does not seem to have functioned this way.

This illuminates the discrepancy between what the students of 2020 stated in the questionnaire and the actual use of the IVS seen in the reports. They seem to overestimate the use of the IVS, which may, as mentioned above, be a result of complying with perceived expectations. Nonetheless, the IVS was used in a practical sense by the students to process their materials and illustrate their findings while learning these archaeological practices.

\section{Conclusion}

Previous studies evaluating education in archaeology have shown the need for more investigation (Cobb \& Croucher, 2014; Colaninno, 2019; Dallas, 2015; Lea, 2020). This study set out with the aim of expanding the field-archaeology pedagogical programs with the integration of 3D visualisation systems to improve and strengthen the deep approach to learning and critical thinking and of estimating the effect of technology on students' education and on teaching.

We can examine the findings of 2 years of experimentation from both learning and teaching perspectives. From a students' perspective, they had no difficulty starting to use the IVS, but did not use it to its fullest potential with all the functions and tools, and moreover, overestimated their use when asked. Most importantly, the IVS was used as a tool for analysis of a combination of units not exposed simultaneously. However, apart from this example, using the IVS for analysis was not very developed. Moreover, the overview provided by the IVS was not fully explored. This is probably connected to the inexperience of the students rather than the potentials of IVS. It was mostly used to create illustrations, and interestingly, the possibilities to go beyond norms were explored. Even though the IVS was fulfilling the needs of the students, we cannot disregard the influence we as teachers and our emphasis on the IVS had, as an explanation of the focus on this tool. When the students could choose another documentation method as a base for illustrations, hand drawing was seen as equally suitable.

From the teaching point of view, we can describe the teacher's role as instructive, when instructing the students at the beginning of the course both during the fieldwork and the post-excavation and providing students with the needed material (the MOLAS manual, the report template, and the previous year colleagues' report). The teachers also had an advisory and supporting role while the students worked in groups both in the field and in the lab week, learning by doing as it occurs with the authentic task. The students become aware and critical when working in a group and when they need to determine what they need themselves. They are responsible for their learning, practising a deep approach to learning.

We expanded the field-archaeology pedagogical programs by combining the integration of 3D visualisation systems to the fieldwork activities framed within the Problem-Based Learning approach to enhance and strengthen the deep approach to learning and critical thinking.

Estimating learning when it happens is impossible (Fox, 1983, p. 51), but PBL offers some possibilities such as peer reviewing and self-assessment. Through self-assessment, students identify the required tasks and monitor their own progress. By sharing samples of students' work with comments before students perform self-assessment, teachers allow students to hone their ability to recognise the qualities of good work (Ambrose et al., 2010, p. 209). We used 'scaffolded instructions', giving the students the outline of the report and their colleagues' reports as a reference for building their reports, without comments on them. They appeared to be useful, but we can do more: for example, implementing them in the system. This way, the students will write their report directly in the system, which will ask them specific questions for filling 
the several sections, which compose the report. By answering them, the students will be able to consolidate their skills in report writing, and once they do not need to answer those questions for writing the report sections, they will not use the scaffolded instructions anymore. Peer review represents another possible solution to perform students' assessment. However, research shows that to be effective, the teacher should give the students specific criteria about the way to do that (Ambrose et al., 2010, pp. 209-210).

We think the use of technologies can help to foster reflexivity thanks to the possibility to virtually reconstruct the excavation environment. Not having mastered the archaeological process yet, the undergraduate students are not able to focus on all the elements they need to interpret their data, and observation and reasoning at the trench's edge are one of these. We have seen that students do reflect on the impact of their own experience on knowledge production and that they have an appreciation of the subjectivity of their interpretations. However, the role of the IVS in this reflexive process is not yet clear. According to our observation, working in a group, going back virtually to their squares could help them to bring new insights compared to what was done in the field. The stone layer that was combined from several units after excavation is an example of this, illuminating this potential.

An additional issue with our study concerns the limited time of the course. We know that the students with no prior knowledge of archaeological excavation learn something from every action they take within the course. However, the limited time is a factor that impacts and limits the opportunities for us to have time to both teach and evaluate the learning process.

In planning this course in the future, we need to take this aspect into account. It could also be worth keeping track of the students who continue their studies in archaeology to observe whether they keep the knowledge and skills learnt during the course.

The findings of this 2 year study seem to be promising, but they are neither definitive nor absolute and, for this reason, need further investigation. Our study, even if not conclusive, sheds light on new pedagogical practices in field-archaeology that can have important implications for future practice.

Acknowledgements: The authors want to thank the coordinating editors Loes Opgenhaffen, University of Amsterdam, Martina Revello Lami, Leiden University, and Hayley Mickleburgh, Linnaeus University, for the opportunity to participate in this issue, as well as the managing editor Katarzyna Michalak at Open Archaeology. We would also like to thank all the archaeology students of the 2019 and 2020 Lund University field course (ARKA22) for their patience and willingness to experiment with the documentation methods, as well as our colleague Andreas Svensson. We are also grateful to three anonymous reviewers for their useful comments.

Author contributions: All authors have accepted responsibility for the entire content of this manuscript and approved its submission. PD designed, developed, and implemented the 2019 and 2020 IVS. PD and ÅB designed the questionnaire. Both authors contributed to all sections, however PD prepared most of Sections 1-4, 6 and ÅB most of Section 5 .

Conflict of interest: The authors state no conflict of interest.

Data availability statement: This study is based on the analysis of student reports, the responses to a questionnaire, and our observations during two seasons of a field course. Our observations include the student use of a specially designed IVS. The datasets generated and analysed in this system are available at https://www. darklab.lu.se/digital-collections/dynamic-excavation/sodra-sallerup/. The questionnaire and the responses are available at: https://docs.google.com/forms/d/1kqY8_4rE0OszM3py4ci9oBwOHACUE1RoQPIwnKYmp8Q/edit? usp=drive_web. All other data are available through the sources listed in the References section. 


\section{References}

Agbe-Davies, A. S., Galle, J. E., Hauser, M. W., \& Neiman, F. D. (2014). Teaching with digital archaeological data: A research archive in the university classroom. Journal of Archaeological Method and Theory, 21(4), 837-861. doi: 10.1007/s10816013-9178-3.

Ahlberg, M., Gisbertz, B., Lindström, H., \& Olsen, E. (2020). Seminariegrävning i Södra Sallerup MMA132 25 maj-5 juni 2020. Unpublished student report. Sweden: Lund University.

Ahnlund Malmberg, S., Hjulström, A., Jacobsen, K., Palm, A., Skeppner, E., \& Sundberg, C. (2019). Seminariegrävning i Södra Sallerup RAÄ 28:1 22-28 maj 2019 Rapport från Grupp F. Unpublished student report. Sweden: Lund University.

Al Khabour, A. (in press). Aprendizaje Basado en el Objeto: El Aula Didáctica Antonio Blanco Freijeiro de la Universidad Autónoma de Madrid. Isimu.

Ambrose, S. A., Bridges, M. W., DiPietro, M., Lovett, M. C., \& Norman, M. K. (2010). How learning works. 7 research-based principles for smart teaching. San Francisco: John Wiley \& Sons, Inc.

Andersen, M., Andersson, N., Ferreira, M., \& Petersen, G. (2019). Seminariegrävning i Södra Sallerup 201922-28 maj 2019. Rapport ruta D6 \& D7. Unpublished student report. Sweden: Lund University.

Bell, S. (2010). Project-based learning for the 21st century: Skills for the future. The Clearing House: A Journal of Educational Strategies, Issues and Ideas, 83(2), 39-43. doi: 10.1080/00098650903505415.

Berggren, Å. (forthcoming). Report Södra Sallerup. Lund University.

Berggren, Å., Dell'Unto, N., Forte, M., Haddow, S., Hodder, I., Issavi, J., ... Taylor, J. S. (2015). Revisiting reflexive archaeology at Çatalhöyük: Integrating digital and 3D technologies at the trowel's edge. Antiquity, 89(344), 433-448. doi: 10.15184/ aqy.2014.43.

Bergman, J., Dahlström, V., Larsson T., \& Lindahl, M. (2019). Arkeologi i praktik i Södra Sallerup 2019, Södra Sallerup RAÄ 28:1, Sallerup 180:26, Malmö kommun. Rapport från grupp 3 \& 4. Unpublished student report. Sweden: Lund University.

Chrysanthi, A., Murrieta Flores, P., \& Papadopoulos, C. (Eds.). (2012). Thinking beyond the Tool: Archaeological computing and the interpretive process: Archaeological computing and the interpretive process. Ann Arbor, MI: University of Michigan Press. doi: 10.30861/9781407309279.

Cobb, H., \& Croucher, K. (2014). Assembling archaeological pedagogy. A theoretical framework for valuing pedagogy in archaeological interpretation and practice. Archaeological Dialogues, 21(2), 197-216. doi: 10.1017/S138020381400021X.

Colaninno, C. E. (2019). The need for discipline-based education research in archaeology. Journal of Archaeology and Education, 3, 25.

Daems, D. (2020). A review and roadmap of online learning platforms and tutorials in digital archaeology. Advances in Archaeological Practice, 8(1), 87-92. doi: 10.1017/aap.2019.47.

Dahlberg, F., Svensson, D., \& Parker, D. (2020). Seminariegrävning i Södra Sallerup RAÄ 28:1 25-29 maj 2020 -Ruta F12, G11, H11. Unpublished student report. Sweden: Lund University.

Dallas, C. (2015). Curating archaeological knowledge in the digital continuum: From practice to infrastructure. Open Archaeology, 1(1), 176-207. doi: 10.1515/opar-2015-0011.

Dell'Unto, N. (2018). 3D models and knowledge production. In Y. Huvila (Ed.), Archaeology and archaeological information in the digital society (pp. 54-69). Abingdon, Oxon: Routledge. doi: 10.4324/9781315225272-4.

Derudas, P., Dell'Unto, N., Callieri, M., \& Apel, J. (2021). Sharing archaeological knowledge. The interactive reporting system. Journal of Field Archaeology, 46(5), 303-15. doi: 10.1080/00934690.2021.1911132.

Evans, T. L., \& Daly, P. T. (2006). Digital archaeology: Bridging method and theory. London; New York: Routledge. Retrieved from http://site.ebrary.com/id/10163521

Fox, D. (1983). Personal theories of teaching. Studies in Higher Education, 8(2), 151-163. doi: 10.1080/03075078312331379014.

Garstki, K. J., Larkee, C., \& LaDisa, J. (2019). A role for immersive visualisation experiences in teaching archaeology. Studies in Digital Heritage, 3(1), 46-59. doi: 10.14434/sdh.v3i1.25145.

Hamilakis, Y. (2004). Archaeology and the politics of pedagogy. World Archaeology, 36(2), 287-309. doi: 10.1080/ 0043824042000261031.

Helle, L., Tynjälä, P., \& Olkinuora, E. (2006). Project-based learning in post-secondary education - Theory, practice and rubber sling shots. Higher Education, 51(2), 287-314. doi: 10.1007/s10734-004-6386-5.

Isaksson, S. (2011). Att undervisa i fält. Principer och praktik. Överleva, 28(3), 18-38. Svenska Överlevnadssällskapet.

Jackson, S. E., Motz, C. F., \& Brown, L. A. (2016). Pushing the paperless envelope: Digital recording and innovative ways of seeing at a classic maya site. Advances in Archaeological Practice, 4(2), 176-191. doi: 10.7183/2326-3768.4.2.176.

Kreber, C. (2002). Teaching excellence, teaching expertise, and the scholarship of teaching. Innovative Higher Education, 27(1), 5-23.

Larsson Ljungström, D., Suominen, S., \& Wirestrand, P. (2020). Unpublished student report. Sweden: Lund University.

Lea, J. E. (2020). Discussion meeting the challenge with an integrated model for archaeology education. Journal of Archaeology and Education, 4(3), 7.

Lock, G. (2006). Computers, learning and teaching in archaeology: Life past and present on the screen. In T. L. Evans \& P. T. Daly (Eds.), Digital archaeology: Bridging method and theory. Abingdon, Oxon: Routledge. http://site.ebrary.com/id/10163521 
Morgan, C., \& Wright, H. (2018). Pencils and pixels: Drawing and digital media in archaeological field recording. Journal of Field Archaeology, 43(2), 136-151. doi: 10.1080/00934690.2018.1428488.

Nielsen, B., \& Rudebeck, E. (1991). Introduktion till arkeologi i Södra Sallerup. En översikt över utgrävningarna kring Ängdala gård. In S. Ersgård (Ed.), Elbogen 1990 (pp. 64-97). Malmo: Malmö kulturhistoriska förening.

Opitz, R., \& Limp, W. F. (2015). Recent developments in high-density survey and measurement (HDSM) for archaeology: Implications for practice and theory. Annual Review of Anthropology, 44(1), 347-364. doi: 10.1146/annurev-anthro102214-013845.

Papadopoulos, C., Chrysanthi, A., \& Murrieta-Flores, P. (Eds.). (2012). Thinking beyond the tool: Archaeological computing and the interpretive process (BAR International Series Vol. 2344). Oxford: Archaeopress.

Perry, S., \& Taylor, J. S. (2018). Theorising the digital: A call to action for the archaeological community (pp. 11-22). In M. Matsumoto, \& E. Uleberg (Eds.), CAA2016: Oceans of Data. Proceedings of the 44th Conference on Computer Applications and Quantitative Methods in Archaeology, 389-398. Oxford: Archaeopress.

Petersén, A., Ekman, E., Vitale, E., \& Osvath, H. (2019). Seminariegrävning i Södra Sallerup Delrapport ruta D11 och D12, Grupp 5 \& 6. Unpublished student report. Sweden: Lund University.

Peuramaki-Brown, M. M., Morton, S. G., Seitsonen, O., Sims, C., \& Blaine, D. (2020). Grand challenge No. 3: Digital archaeology technology-enabled learning in archaeology. Journal of Archaeology and Education, 4(3), 4.

Ponchio, F., Callieri, M., Dellepiane, M., \& Scopigno, R. (2020). Effective annotations over 3D models. Computer Graphics Forum, 39(1), 89-105. doi: 10.1111/cgf.13664.

Potenziani, M., Callieri, M., Dellepiane, M., Corsini, M., Ponchio, F., \& Scopigno, R. (2015). 3DHOP: 3D Heritage Online Presenter. Computers \& Graphics, 52, 129-141. doi: 10.1016/j.cag.2015.07.001.

Potenziani, M., Callieri, M., \& Scopigno, R. (2018). Developing and Maintaining a web 3D viewer for the CH community: An evaluation of the 3DHOP framework. In Sablatnig, R. \& Wimmer, M. (Eds.), Eurographics Workshop on Graphics and Cultural Heritage. Vienna: Eurographics Association. doi: 10.2312/GCH.20181356.

Rudebeck, E. (1994). Ängdala och meningen med arkeologin. Arkeologi i Sverige, 3. Stockholm.

Svensson, E., Sarpehöök, J., Wendt, H., \& Radtke, M. (2019). Seminariegrävning 2019 i Södra Sallerup RÄ̈ 28:1 - Rapport från grupp 7 och 8 . Unpublished student report. Sweden: Lund University.

Synnestvedt, A. (2015). Högskolepedagogik i arkeologiämnet - ett intresse eller en icke-frågaHögskolepedagogiska texter, Enheten för pedagogik och interaktivt lärande. Sweden: Göteborgs universitet.

Trigwell, K. (2006). An analysis of the relations between learning and teaching approaches. Lifelong Learning: Concepts and Contexts. In P. Sutherland, \& J. Crowther (Eds.), Lifelong learning: Concepts and contexts (pp. 108-116). London: Routledge.

Wilhelmson, H., \& Dell'Unto, N. (2015). Virtual taphonomy: A new method integrating excavation and postprocessing in an archaeological context. American Journal of Physical Anthropology, 157, 305-321. 